\title{
Queer Ways of Relating in Contemporary Estonia
}

\author{
Tuuli Innola
}

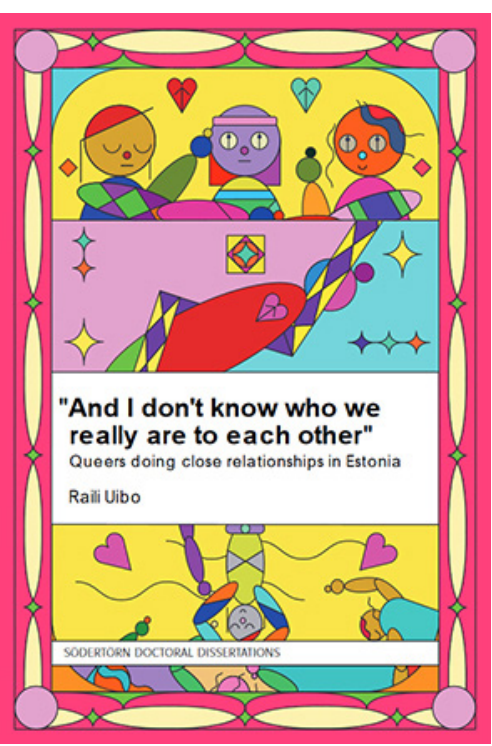

Uibo, Raili.2021. "And I don'tknow who we really are to each other": Queers doing close relationships in Estonia. Södertörn University, School of Culture and Education, Gender Studies.

http://sh.diva-portal.org/smash/get/ diva2:1548932/FULLTEXT01.pdf

"It was so funny that it was Christmas and she was suddenly sitting with us on the same sofa and eating with us. Everyone had a strange face, like 'What is happening now?' But we all finished eating and all departed in a friendly manner. Very odd."

Raili Uibo's doctoral thesis in Gender Studies "And I don't know who we really are to each other": Queers doing close relationships in Estonia is lively and nuanced research on how queers in Estonia live and experience their close relations and how they negotiate their queerness in everyday life.
Uibo examines the lived reality of close relations, based on interviews, survey data and fieldwork, and builds the analysis on situated and contextsensitive theoretical knowledge. The quote above concerns a situation where queerness is made visible to the interviewee's family of origin but not explicitly brought up - this is an example of an opaque strategy of negotiating queerness, to which Uibo dedicates one of the analytical chapters. The book also offers a useful overview of the historical, material, and social conditions of being queer in Estonia. The analysis develops theoretically and empirically interesting knowledge on how the complex entanglements of closeness, care, and recognition shape the realities of a good life in a neo-liberal and heteronormative culture with Soviet history. The study is part of a larger research project "Queer(y)ing kinship in the Baltic Region" and contributes specifically to the research fields of queer intimacies and area studies focusing on Central Eastern European and Baltic region.

\section{From families to close ones}

When Uibo was in the beginning of her research, she went to Estonia and approached her informants asking about their "queer families". She explains realizing that her conceptualisation, which was informed by previous research on queer intimacies as "families", did not quite make sense to 
many of her informants. They were confused if they should talk primarily about their families of origin or if they were assumed to have children of their own. Uibo then soon shifted her emphasis from the original idea of queer families to close ones (in Estonian lähedased). A considerable part of the participants' close relationships was something they simply did not perceive as "a family". Close ones as a starting point does enable to examine those relations that are understood as family but also expand towards other kinds of relationships that are experienced as important. Consequently, the lived realities of close relationships open as complex and messy webs of relations filled with love, commitment, and intergenerational support, but simultaneously constrained by the lack of acceptance and recognition.

The analysis provides a rich and detailed account of how queer relationships are made, maintained, broken, and informed in everydaylife, and how being queer in Estonian society becomes part of these processes. The study is carried out by doing five months of ethnographic fieldwork and collecting interviews $(\mathrm{N}=19)$ and a qualitative online survey $(\mathrm{N}=302)$. The three analytical chapters of the book have plenty of citations from the interview data and the first one circulates around the "close relationship maps" that the interviewees drew during the interview situations. The relationships in focus vary from friendships, colleagues, and romances to family and blood relations and the analysis follow varied kind of everyday routines, encounters and relating. Uibo successfully avoids fixing any essential differences between the varied kind of close relationships but examines the shifting roles and blurring definitions of close relationships.

It is not always easy to define who the close ones really are, and the different practices and understandings of closeness are at the core of the book. Queer intimacies may escape clear definitions not only because relationships tend to be mobile in the first place, but also because they move within specific temporalities, affective landscapes, and meaning-makings. Uibo examines what it means for the relationships to be formed outside the strong affective pull of "happy objects" (Ahmed 2010), such as ideals of the heterosexual nuclear family, and shows how queer intimacies may be left unnoticed by the heteronormative gaze when the relationships are not specifically disclosed by speech acts. This is demonstrated with the quote in the title of the book: "And I don't know who we really are to each other".

\section{Queer lives in Estonian context}

A chapter "Estonian queer lives in time and space" comes before the analytical chapters and provides background information of the context of Estonia as a historical, socio-cultural, and economic setting of the study. This chapter comes out as useful and even necessary for understanding the following analysis. For a reader like me, living in a neighboring country with some contacts to Estonia, the book still provides eye-opening information and reflection on local and temporal conditions for living a queer life. The history of gaining independence and separating from Soviet Russia, followed by a quick and harsh move towards neoliberal austerity politics with little state support and limited possibilities for making an adequate living, influences the ways of understanding gender, family, and ideas of social success, in multifaceted and sometimes subtle ways.

Queer rights are as controversial issues in Estonian public debates as ever. Despite that the Registered Partnership Act passed in 2014 and entered into force in 2016, its implementation has not been successful in providing equal rights and protection. The institution of marriage has lost its appeal to a large part of Estonians and the marriage rates are the lowest in Europe, and simultaneously the divorce rates are high. Still, the strong emotional hold to the heteronormative imaginary of nuclear family prevails and there is little actual support for LGBTQ rights. Queer communities 
themselves struggle to exist in a hostile environment where political activity is not attractive for many, and where a cultural cleavage between Estonian-speaking and Russian-speaking populations divides Estonians (queers and others alike) into two groups. This division consists of both imaginary ethnic and cultural borders and geographical segregation. The Russian-speaking population faces a lack of recognition also within the queer movement. Uibo's study navigates through this dividing line and questions also the East/West divisions that have long been part of the studies concerning Eastern European societies.

\section{Queer opaque as a strategy in precarious conditions}

The affective practices of kinship-making are examined throughout the book particularly within the context of economic precarity. Precarity shapes the conditions for living a queer life: how to relate to relatives and family members with hostile attitudes towards LGBTQ minorities while being dependent on their support? How to care for your loved ones and negotiate the chrono-normative pressures to succeed in a society where queerness is associated with failure? How to form "families of choice" when precarious life situations prevent making choices of your own?

The development of the concept of queer opaque is one of the most important theoretical virtues of the study. Uibo presents the concept, originally by a film and queer studies scholar Nicholas de Villiers (2012), to analyse practices of negotiating queerness that exceed the binaries of visibility and invisibility. Queer opaque can be seen as a strategy to sustain good relations with the surroundings while living a queer life. This is demonstrated by several examples from the interview data, where participants talk about living openly as a queer but simultaneously avoiding such acts that would make their queerness visible. Situating queer opaque to the precarious life-situations in Estonia, Uibo shows that these ambiguous strategies of opaque are certainly connected to inequalities and homophobic logics of shame, but nevertheless can include enabling and freeing potentialities.

Importantly, while some practices are easily interpreted as merely oppressive and characterized by internalized homophobia when examined through the lens of Western European or US-based feminist knowledge, the freeing and life-sustaining elements of these tactics unfold when studied from a context-sensitive perspective. Uibo shows how the popular cultural narratives of "coming out" or "being in a closet" do not always make sense in the lives of queer Estonians and are insufficient tools for understanding the precarious practices of negotiating queerness. Silences, willed ignorance, and quiet allyships become important in maintaining close relations in precarious economic situations and in an environment where a strong affective pull towards traditional gender patterns and heterosexuality prevails as heavily dominant.

\section{Meandering but embedded account on close ones}

The careful contextualization becomes one of the main strengths of this book and it works as a cornerstone for a sprawling study that aims to draw a picture of a wide and multifaceted topic. The study deals with a broad number of issues concerning intimacy and contributes to discussions with a long tradition in the feminist and queer knowledge production. The analysis is still insightful and captivating enough for the reader to bear with the sprawled-out issues at hand. The research findings stand on a firm ground due to thoroughly considered and situated perspectives, theoretical frameworks, and conceptualization. Uibo discloses and elaborates her methodological and theoretical perspectives and considers 
her own positionality in a relevant and deeply feminist manner. The book is also generally well structured and easy to follow. Only, the purpose of the short interlude-sections between each chapter do not really open up, as their contents do not noticeably differ from the analytical chapters. Also, the role of the varied data collection methods, other than the interviews (ethnographical fieldwork, survey, and research diary), remain a bit unclear

in respect of the main arguments and findings. The value of these different types of data and their part in the knowledge production could have been elaborated more clearly.

Uibo includes all those human relations that are important in the lives of the participants into the scope of her study - not only romantic or sexual relationships or those understood as "a family". This proves to be essentially fruitful in shedding light on the complexity and multidimensionality of closeness, kinship, and intimacy in queer lives in Estonia. Intimate relations are approached with sensitivity to non-normative relationship constellations and blurred lines of intimacies, without excluding those relationships that get their meanings through normative understandings of couple-relationships and family. This research thus becomes a valuable and timely contribution to the research field dealing with queer intimacies in general, and a unique and important addition to the field of empirical research on queers in the Central Eastern European, and particularly in Estonian, context.

\section{References}

Ahmed, Sara. 2010. The promise of happiness. Durham \& London: Duke University Press.

De Villiers, Nicholas. 2012. Opacity and the closet: Queer tactics in Foucault, Barthes and Warhol. Minneapolis: University of Minnesota Press. 